\title{
Oil Spill Damage to a Large Marine Ecosystem: The Gulf of Mexico (GoM)
}

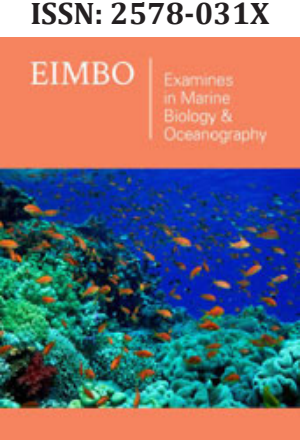

*Corresponding author: : Luis A Soto, Instituto de Ciencias del Mar y Limnología after Limnología, Universidad Nacional Autónoma de México, México

Submission:

Published: 㟵August 08, 2019

Volume 3 - Issue 1

How to cite this article: Luis A Soto.Oil Spill Damage to a Large Marine Ecosystem: The Gulf of Mexico (GoM). Examines Mar Biol Oceanogr. 3(1). EIMB0.000554.2019. DOI: 10.31031/EIMBO.2019.03.000554

Copyright@ Luis A Soto, This article is distributed under the terms of the Creative Commons Attribution 4.0 International License, which permits unrestricted use and redistribution provided that the original author and source are credited.
Luis A Soto*

${ }^{1}$ Instituto de Ciencias del Mar y Limnología after Limnología, Universidad Nacional Autónoma de México, México

\section{Opinion}

After nine years of the Deepwater Horizon (DWH) catastrophic environmental accident in the northern Gulf of Mexico, there is a consensus among the different stakeholders about the severe damage inflicted to the health of this vital marine ecosystem. The massive gas and spilled crude oil, and other toxic compounds had no precedent in the annals of the world oil industry. The primary concern in the early phase of the accident was focused on containing the "black-tide" at the surface. Unfortunately, the efficiency of direct recollection, selective burning, and chemical dispersion at the Macondo's wellhead were not satisfactory. To make things worse, British Petroleum's decision to inject considerable quantities of chemical dispersant at the borehole only augmented the complexity of the spill. Extensive surface and subsurface (500-800-1200m) oil plumes originated in the northern Gulf whose trajectories threatened other sectors of the Gulf. Early predictions of the possible pathway of the oil slicks at the surface waters had a certain degree of accuracy; synoptic remote sensing techniques observations conducted by the National Oceanic and Atmospheric Administration (NOAA) contributed to defining the emergency procedures and the field observations in the USA's waters.

Indeed, the capping of the uncontrolled wellhead after nearly four months of emergency proved a significant challenge for underwater technology. However, the DWH incident left a painful experience for many sectors of our society. One the one hand, it revealed the gross negligence of a giant oil company operating in deep-waters, and on the other, the high uncertainty concerning the immediate and long-term effects of the spilled oil. Many are the factors that determine the final destiny of complex oil molecules in the marine ecosystem. Coastal habitats (lagoons-coral reefs-marshlands-mangroves), open waters and, seabed are vulnerable to oil contaminants due to the lasting effects of toxic compounds incorporated in the trophic-web or deposited in shallow and deep sediments.

Currently, there are more than 600 scientific contributions that have intended to disclose any of the questions raised by the unusual injection of a high volume of gas and crude oil in the GoM. Some authors are optimistic about the rapid physical, and ecological recovery the GoM has shown arguing that the harmful effect was confined to the vicinity where the accident occurred. In contrast, other colleagues have voiced concern about the long-term (two-three decades) environmental injuries. In the present commentary, I have avoided recapitulating information already divulged concerning the DWH [1]. Instead, I would like to call the attention around two fundamental principles: 2

A. The existence of trans-boundary pollutants in the GoM.

B. The high connectivity of oceanographic processes within the GoM.

For Mexico, these two concepts are essential to understanding the potential environmental consequences of a massive oil spill in its Exclusive Economic Zone (EEZ) and coastline. Given the surface ocean circulation prevailing in the GoM, Macondo's oil slicks were trapped in the Loop Current (Eddy Franklin Gyre), invading, later on, the waters nearly $700 \mathrm{~km}$ off the Yucatan Peninsula. Mexico's National Biodiversity Commission (CONABIO) downloaded NOAA's satellite images that exhibited the slicks [2,3]. Mexican fishermen from the Tamaulipas and the northern coast of Veracruz testified the incidental arrival of tar-balls along the beach in the aftermath of the DWH event. 
The above two conditions facilitate the active transport of contaminants across different sectors of the Gulf. There are no physical barriers or other sorts of factors that impede the free passage from USA's waters towards Mexico's EEZ [4]. Migratory species (trans-boundary species) and planktonic larvae take advantage of the ocean circulation to extend their functional niche (growth-reproduction-nutrition) within the Gulf, regardless of international legal boundaries [5]. The Ixtoc-I blowout of 1979, and the Harmful Algal Blooms (HAB) are living proof of the high connectivity among the sectors of the GoM. The Ixtoc-I took place in the offshore water of Campeche Sound, and its effects were felt as far north as the Texas shoreline. Another example of the high connectivity within the GoM is that of harmful algae (planktonic dinoflagellate) from the Yucatan Peninsula. These microscopic algae can be advected by surface currents to the Florida Peninsula, blooming there and causing red tides [6-8].

During the 3-year survey, that I conducted in northwestern GoM, covering Mexico's EEZ from 50 to $1300 \mathrm{~m}$ in anticipation to the deleterious effects of the DWH sinking, particular attention was given to detecting any anthropic alteration in the pelagic or benthic realms. The summer of 2010 served to build the baseline data bank of more than 40 abiotic and biotic variables. The monitoring of the general oceanographic conditions in the succeeding two years contributed to targeting the metaanalysis on variables displaying significant changes from their normal pattern. Among those variables were the benthic infaunal communities, benthic biomarkers, Oil Mineral Aggregates (OMA), Polycyclic Aromatic (PAH) and aliphatic hydrocarbons contained in surface sediments. The benthic infaunal communities enable us to document the interannual variation in their composition and biomass. It was concluded that 2010 had a healthy condition; 2011 was a transitional year, but 2012 exhibited significant alterations produced by anthropic factors resulting from the Macondo oil spill. Similarly, the proliferation of specific biomarkers (nematofauna) in surface sediments was stimulated by the increasing concentration of hydrocarbon derivatives, and the exclusion of other components due to increased toxicity levels. These findings were nicely correlated with the presence of small particles of oil mineral aggregates detected along the outer continental shelf and upper slope off Tamaulipas. Such particles were coated with weathered oil whose mineral composition corresponded to phyllosilicates from continental sources. In the northern GoM, the Mississippi River is the primary source of these minerals that when exposed to crude oil promotes the so-called "marine snow" deposited on the seafloor.

The concentration levels of PHA, Aliphatic hydrocarbons and trace metals in sediments maintained tolerable concentration trends within the EPA's benchmarks. However, they began to exhibit a 3 increasing trend in 2013 surpassing the accepted ranges to ensuring healthy conditions. Trace metal like nickel and vanadium are perhaps the best examples of such an increasing trend in the studied area. Attempts to correlate the alleged fingerprint of Macondo's oil $(\delta 13 \mathrm{C}-27.0 \%$ ) with that estimated (average $\delta 13 \mathrm{C}$ $-21.0 \%$ ) for surficial sediments in our survey were not effective.
Oil biodegradation, carbon fractionation in the trophic web, and weathering factors possible accounted for this analytical failure. Nevertheless, fluorometry observations practiced by colleagues from the Mexican Petroleum Institute (IMP) in 2013 provided undisputed evidence on the long persistence of hydrocarbon compounds in the deep-waters of Mexico's EZZ.

Numerous authors have voiced concern about extending future oil exploration and extractions of fossil fuel from ecologically fragile deep-sea habitats in the GoM. Even though there were significant deployments of human and technical resources to examining the environmental consequences of the DWH accident, particularly in the USA and in less magnitude in Mexico, many are the questions that remained unanswered. Issues as the total volume of oil released by the Macondo blowout, its final destiny and long-term persistence in the ecosystem are not entirely elucidated. The economic damages inflicted by the massive oil spill on the general ecological services provided by the GoM to bordering countries like Mexico remain unsettled. In spite of international treaties acknowledged by the two countries, compensatory economic damages to the USA waters by BP amounted to $\$ 16.67$ US billion whereas in the case of Mexico's EZZ, BP did not admit any damage and approved compensatory funds (\$1.2US million) to cover for Mexico's emergency monitoring procedures conducted at the outset of the DWH event $[9,10]$.

In summary, based on our scientific findings contained in our publications (see references) and, my personal experience, undoubtedly, there is sufficient evidence revealing the injury caused by the DWH disaster in Mexican territorial waters. We contend that transboundary pollutants and the existing connectivity within the Gulf of Mexico expanded the Macondo' oil spill damages to the fragile continental shelf and deep habitats of the northwestern Gulf of Mexico. The economy of essential ecological services provided by the Gulf, such as the exploitation of living resources and recreational activities was severely impacted at the outset of the oil spill. But more importantly, long-term toxic effects derived by persistent hydrocarbon compounds in the marine ecosystem still represent a serious threat to the economy of the fishing industry of the Mexican Coastal States and waters in the Gulf.

\section{Acknowledgment}

The author's research is being funded by the Instituto de Ciencias del Mar y Limnología, Universidad Nacional Autónoma de México

\section{References}

1. Beyer J, Trannum C, Torgeir B, Hodson PV, Collier K (2016) Environmental effects of the deepwater horizon spill: A Review. Marine Pollution Bulletin 110(1): 28-51.

2. Botello A, Soto LA, Ponce Vélez G, Villanueva S (2015) Baseline for PAHs and metals in NW Gulf of Mexico related to the Deepwater Horizon oil spill. Special Issue Changes to processes in estuaries and coastal waters due to intense multiple pressures. Est Coast Shelf 4: 124-133.

3. Botello AV, Ponce VG, Soto LA, Villanueva FS (2018) The issue of fossil fuels at the ocean: Emissions to the sea and contribution to global $\mathrm{CO}_{2}$. In: Arias AH, Marcovecchio JE (Eds.), Marine Pollution and Climate Change CRP. Taylor \& Francis Group, New York, USA, pp. 66-98. 
4. Botello AV, Ponce Vélez G, Soto L A, and Villanueva, FS (2018b) Chapter 1 Black Tides: Petroleum at the Ocean. Section I: General Pollution on coastal and Deep ocean environments. In: Arias AH (Ed.), General pollution in coastal and deep ocean environments.

5. Salcedo DL, Soto LA, Estradas Romero A, Botello AV (2017) Inter annual variability of soft bottom macrobenthic community of the NW Gulf of Mexico in relationship with the DWH oil spill. Mar Poll Bull 114(2): 987994.

6. Soto LA, Vázquez BA (2013) Legal issues and scientific constraints in the environmental assessment of the deepwater horizon oil spill in Mexico Exclusive Economic Zone (EEZ) in the Gulf of Mexico. International Journal of Geosciences 4(5): 39-45.

7. Soto LA, Botello AV, Licea DS, Lizárraga PML, Yáñez AA (2014) The environmental legacy of the Ixtoc-i oil spill in campeche sound, southwestern W Gulf of Mexico. Frontiers in Marine Sciences.
8. Soto LA, Salcedo D, Arvizu K, Botello VA (2017) Interannual patterns of the large free living nematode assemblages in the Mexican Exclusive Economic Zone, NW Gulf of Mexico after the deepwater horizon oil spill. Ecological Indicators 79: 371-381.

9. Zubillaga A, Soto LA, Salcedo DL, Botello AV (2018) Presence of Oil Mineral Aggregates (OMAs) in surface sediments from Mexico's Exclusive Economic Zone, NW Gulf of Mexico. Bull Environ Contam Toxicol 101(2): 173-177.

10. Soto LA, Estradas RA, Salcedo OD, Botello AV, Ponce VG (2018) The hazards of monitoring ecosystem ocean health in the Gulf of Mexico: A Mexican perspective. In: Bachari FH (Ed.), Monitoring of Marine Pollution, Intech Open, London, UK. 